\title{
Intención historiográfica y sujetos de relato en Hombres de mar, de Óscar Colchado Lucio ${ }^{1}$
}

\section{Historiographical intention and subjects of story in Hombres de mar by Óscar Colchado Lucio}

Estefanía Peña Steel ${ }^{2}$

Universidad Austral de Chile, Valdivia, Chile | Universidad Santo Tomás, Valdivia, Chile estefania.pena@docentes.uach.cl | epena4@santotomas.cl

\section{RESUMEN}

Pensar en las literaturas heterogéneas - particularmente en la narrativa andina - y en sus posibilidades critico-teóricas implica, necesariamente, pactar con la historia y con sus voces silenciadas. En la novela Hombres de mar (2011), de Óscar Colchado Lucio, este imperativo se concreta mediante la intención historiográfica y la presencia de sujetos de relato. Estos mecanismos textuales de resistencia operan como fuentes de interpretación y discursividad histórica otorgando validez y reconocimiento a posiciones discursivas, lenguas, prácticas culturales y políticas, marginalizadas, pero en permanente resistencia frente al olvido y la discriminación.

\section{PALABRAS CLAVE}

Narrativa andina, discurso historiográfico, discursos de resistencia, Hombres de mar, Óscar Colchado

\section{ABSTRACT}

Thinking about heterogeneous literatures-particularly in the Andean Narrative-and on their critical-theoretical possibilities necessarily involves pacing with History and their silenced voices. In the novel Hombres de mar (2011), by Oscar Colchado Lucio, this imperative is concretized by

1 Este trabajo formó parte del Proyecto Fondecyt Regular 1141007, «Reterritorialización en las literaturas andino-amazónicas: poéticas y enunciaciones heterogéneas en confluencia», de la investigadora principal doctora Claudia Rodríguez, 2014-2015.

2 Magíster en Literatura Hispanoamericana Contemporánea y candidata a doctora en Ciencias Humanas. Docente del Instituto de Lingüística y Literatura de la Universidad Austral de Chile y coordinadora del Área de Lenguaje de la Universidad Santo Tomás, Valdivia. 
the historiographic intention and the presence of subjects of story. These textual mechanisms of resistance operate as sources of historical interpretation and discursiveness, granting validity and recognition to discursive positions, languages, cultural and political practices, marginalized, but in permanent resistance to forgetfulness and discrimination.

\section{KEYWORDS}

Andean narrative, historiographic discourse, speeches of resistance, Hombres de mar, Óscar Colchado

\section{Narrativa andina: en las elisiones de la historia. Introducción}

Pensar en las literaturas heterogéneas, particularmente en la narrativa andina y en sus posibilidades critico-teóricas, implica, necesariamente, pactar con la historia y con la necesidad mayor de nuestros sistemas literarios de enmendar, como lo ha indicado lúcidamente Antonio Cornejo Polar (1989), «los errores de una historiografía que hace uno de lo diverso y convierte en homogéneo lo que a todas luces es heteróclito siempre en busca de un Orden tan perfecto y armonioso como hechizo» (p. 19). Nos preguntamos entonces, ¿cómo hacen frente, las literaturas andinas, al discurso monológico de la historia y a sus representaciones basadas en la desigualdad e injusticia social?

Para una respuesta tentativa creemos necesario destacar, en principio, algunos aspectos determinantes en las narrativas andinas; a saber: a) el énfasis que la narrativa andina coloca en el nivel del discurso, a diferencia de lo que ocurre en la literatura indigenista, cuyo punto de acción es fundamentalmente el de la historia (Osorio, 1995); b) el vínculo entre el mundo intratextual representado y la realidad extratextual vivida, especialmente, en lo que respecta al abordaje de la violencia y sus formas de manifestación: simbólica, física, espacial, situación que da sustento al categórico supuesto de Degregori (2007), cuando afirma que «el mérito de explorar el tema de la violencia en la literatura peruana pertenezca a los escritores andinos» (p. 61); c) la preocupación historiográfica y testimonial que busca rescatar el «hecho histórico» como parte del discurso literario, desinstalando los relatos oficiales. En este sentido es que la narrativa andina es «un testimonio y una crónica», como ha apuntado Dante Castro (2005).

Con todo, los elementos que aquí hemos descrito a modo de síntesis, se mueven bajo un doble eje problemático: el proyecto/concepto de «nación» y el no menos espinoso proyecto/concepto de «modernidad»; ese denso y siempre irresuelto trayecto histórico-social de negociaciones, con 
nuestra modernidad conflictiva (Ortega, 2010).

Siguiendo el imperativo planteado por Corneo Polar (1989), respecto a la necesidad de revisar y discutir el rol de la historia en la conformación de nuestros sistemas literarios, y considerando que la narrativa andina contemporánea, como hemos visto, tiene una matriz estético-social determinada por el discurso, sus voces y la preeminencia del testimonio como insumo y fuente de interpretación, nos hacemos las preguntas - sencillas en apariencia-: ¿quién «dice» en el texto literario? y ¿desde dónde se «dice»?

Pues bien, en la novela Hombres de mar (2011), del escritor ancashino Óscar Colchado Lucio, estas interrogantes se «resuelven» o, más bien, dan cuerpo a lo que hemos Ilamado «intención historiográfica». Con ello, apuntamos a la insistencia del texto literario por operar como fuente de interpretación y discursividad histórica ${ }^{3}$, de manera que las lógicas del discurso histórico hegemónico-macropolítico se ven forzadas en el texto a la apertura de referentes, y a otras formas y singularidades de representación del mundo, como ocurre en las literaturas culturalmente heterogéneas. Lo que nos parece aquí más relevante es la posibilidad de develar por medio de estas textualidades, las formas en que otras «alternativas existenciales», al decir de Cornejo Polar (1989), comprenden, experimentan y se inscriben en la práctica discursiva de su propia historia (1989, p. 20).

Ahora bien, la idea de «intencionar» un texto releva la figura de un sujeto-autor que tanto interpreta y otorga significados a los acontecimientos, como designa y determina quiénes llevarán la voz del relato historiográfico inscripto en el texto. En este sentido, parece plausible advertir las evidentes correspondencias entre el productor de estas narrativas heterogéneas y el historiador y sus respectivos «ejercicios disciplinarios». Ambos productores de relato, en sus atributos de decidir qué se dice, cómo se dice y desde dónde se dice, practican —o deberían «propender hacia»una escritura ética (Huamán, 2006), en el entendido de que, como lo ha indicado Arthur Danto (1989), el historiador -y en este caso, el sujetoautor de narrativas heterogéneas - nos es «simple observador, sino que adopta el punto de vista de un sujeto, participa y, por tanto, delibera, sopesa decide» (p. 17).

Tal como lo haría el historiador, el autor en este tipo de textualidades recurre a la documentación; proceso que en este caso, no implica necesaria y únicamente la exhaustiva revisión del pasado en el «papel»

3 En términos básicos, entendemos aquí por «discurso de la historia» la manera en que el historiador «expone» o «escribe» la realidad investigada y los proseos mediante los cuales la narración histórica se organiza y, al mismo tiempo, se interpreta (Birulés, 1989). 
o en el archivo, sino que la documentación es entendida aquí como la vivencia personal del hecho histórico narrado. De ahí que en estas obras, para decirlo en los términos de Harshaw (1984), el campo de referencia externo y el campo de referencia interno, son indisociables ${ }^{4}$. La reconstrucción histórico-textual se levanta desde la relación cercana, documentada y vivencial del sujeto-autor con el espacio extratextual ${ }^{5}$. En efecto, afirma Colchado:

yo gocé y padecí la vida de los pescadores en Chimbote debido a que en mi juventud fui obrero por temporadas en la flota pesquera de una fábrica. Estuve en Chimbote desde mi infancia. Yo nací en los Andes, en Áncash, pero a los 5 años mis padres me trasladaron al litoral, y ahí pasé mi infancia, ahí tuve toda mi educación. Ayudaba a un pariente que era mecánico de lanchas. Entonces, cuando tenía vacaciones en mis estudios, yo trabajaba en los muelles, ayudando a reparar lanchas. Ahí fui conociendo a los pescadores, los vi de cerca; tenía también familiares que eran pescadores, amigos de mi barrio, es decir, el mundo de la pesca estaba muy entronizado en mí debido a esas vivencias, porque yo he participado en todas las actividades de los hombres de mar (Colchado, 2015) .

La transversalidad del testimonio en la articulación textual otorga peso existencial a la obra. Nos referimos a la importancia del discurso de la vivencia perteneciente a la «trama» extratextual, pero que colabora en el espesor del texto como insumo o subtexto. Destacamos las formas particulares e híbridas ${ }^{7}$ que asume el testimonio en la novela de Colchado, pero nos interesa la «forma» en función de las implicancias y connotaciones de fondo que esta modalidad despliega en la obra. Nos preguntamos: ¿qué relación tiene el testimonio en el acto de referir, es decir, de «volver a traer» en el texto literario? En un primer atisbo, podemos considerar el testimonio en su calidad de espacio de memoria personal, pero aquí co-

4 Para el estudio de estas categorías y su relación con la ficción y la representación, sugiero el excelente análisis de Dorian Espezúa, en su artículo «Ficcionalidad, mundos posibles y representación».

5 Consideremos la última obra de José María Arguedas y la importancia de la vivencia en su configuración textual. Recordemos que la estadía del autor en Chimbote serviría para explorar y analizar la realidad sociocultural en lo que se supone sería una etnografía, pero que se transforma en material testimonial para la que es su obra más extrema.

6 En entrevista personal con el autor, 25 de setiembre de 2014.

7 Nos referimos a la «hibridez» del testimonio para referirnos a cierta recuperación documental del sentido histórico que pacta con la ficción en varios niveles; uno de estos tiene que ver o se vincula con el uso del «manuscrito encontrado» que incorpora el autor basándose en referentes extratextuales, al inicio de la obra. Este se presenta como un fragmento autobiográfico de un cuaderno perteneciente al militante senderista Manuel Rojas Padilla; al final de este escrito, el «autor» agrega entre paréntesis y con letra cursiva (texto manuscrito hallado entre las pertenencias de Manuel Rojas Padilla, muerto a balazos por la policía antiterrorista, luego de su participación en un atentado dinamitero en la ciudad de Lima el 29 de agosto de 1989) (Colchado, 2011, p. 10). 
labora en la recuperación narrativa de sentidos históricos. En este caso, aunque el testimonio no se despliega explícitamente en el texto literario, sí subyace en la novela como una enunciación equidistante que se infiltra desde la materia extra-textual y autobiográfica, entendida esta última como «documentación». Nos interesa el texto, pero también, salir de este, pues ¿cómo no hacerlo si estamos frente a una escritura ética? Seguimos en este sentido, parafraseando a Roger Chartier (1999), para quien la figura del autor no podría entenderse separada de la realidad y la experiencia fenomenológica del escritor como individuo singular (p. 12).

Esta «posición» escritural ligada al testimonio subyacente en la intención historiográfica se expresa, también, a través de marcas referenciales $y$ «objetividades concretas» ${ }^{8}$ que reclaman en el texto y en el relato una realidad extra-textual, de manera tal que la escritura y el lector se sitúan más allá de la ficción, diremos, en un punto de re-construcción histórica. Con «objetividades concretas» hago referencia, en este caso, a las marcas más evidentes de intención historiográfica en el texto, como fechas de hitos y acontecimientos, nombres de sujetos históricos u otros guiños de ese orden. Estas huellas de «realidad» extra-textual más evidentemente reconocibles en el texto son el primer eslabón en la interpretación histórica. Desde luego, esta estrategia textual va más allá de poner en discusión el binomio «ficción/ realidad» — cuestión ampliamente debatida por lo demás ${ }^{9}$ — o de la «comprobación» de referencias. Lo que nos interesa aquí es analizar los mecanismos que articulan y movilizan en el texto la intención historiográfica y las formas en que posiciones culturales y tradiciones diversas expresan prácticas históricas.

8 Tomo prestada la noción del antropólogo peruano Pedro Jacinto Pazos, en su artículo «Realidad y ficción: las huellas del "Loco Moncada" en el imaginario popular a fines de los noventa en Chimbote» (2004). En este interesante trabajo, Pazos analiza las implicancias y proyecciones extratextuales del personaje social rescatado por Arguedas en Los zorros.

9 De ello se ha encargado profusamente la filosofía de la historia, aunque sin dudas es Hyden White quien acierta al pensar en las posibilidades historiográficas del texto literario, lo que implicaría, por una parte, confrontar las versiones de la historia oficial y, por otra, repensar la relación binaria realidad/ficción entre esta y la literatura. Esta tensión ha sido atendida por White $y$, en alguna medida, resuelta cuando «se atrevió» a afirmar que la historia comporta «ficciones verbales cuyos contenidos son tanto inventados como encontrados» (2003, p. 108). De ahí que el discurso historiográfico transa necesariamente con la imaginación, la memoria, la subjetividad y, más aún, con la intención político-ideológica del historiador (White, 1992). Ya no se trataría, según White, de «elegir entre la objetividad o una visión distorsionada» de la realidad, sino de plantear estrategias para la "constitución de la "realidad" en el pensamiento» (1992, p. 78).

A partir de la idea de «objetividad concreta» de Pazos, nos interesa ampliar la noción y enfatizar lo concreto, en términos de lo «real», pero en la dinamicidad que el texto literario le otorga a lo «real». 


\section{Contar, narrar, reescribir}

En Hombres de mar, la intención historiográfica se articula como una confluencia de sistemas, tradiciones y prácticas culturales e historiográficas que cobran voz en la presencia de sujetos de relato. Nos referimos con esta noción, al mecanismo discursivo de resistencia que pone en valor la «existencia real» de sujetos sociales cuyas voces, recuperadas desde el discurso social, operan en el texto literario como constructoras de enunciación histórica. Y aquí, conviene aclarar que cuando hablamos de discurso social lo hacemos entendiendo los discursos como «hechos sociales» y luego como «hechos históricos» (Angenot, 2010, p. 23). Se sigue de lo expresado hasta aquí, que la heterogeneidad sociocultural y discursiva en esta novela tiene su expresión más concreta, precisamente, en la presencia de estas subjetividades productoras de discurso historiográfico.

Los sujetos de relato no pueden ser pensados como mera ficción o únicamente entendidos desde el constructo «personaje». Sus presencias en el texto literario abren paso, más bien, a la idea de un sujeto productor de sentido histórico y desde este punto de vista, actúan no solo como «objetividades concretas», sino como «objetividades dinámicas» ${ }^{10}$, por cuanto remiten a un referente «real» y remueven los espacios de creación y transmisión cultural centralistas ligados, en este caso, a las hegemonías histórico-sociales y culturales limeñas. Sus voces en el texto literario amplían las perspectivas y puntos de observación historiográfica.

Bajo este enfoque, habremos de tomar distancia del sentido foucaultiano ${ }^{11}$ de «autor», ya que en estas obras ni el «autor» puede ser reducido a una «función» ni los personajes o, por lo menos, algunos de ellos, pues en estas narrativas beligerantes y con fuerte sentido ético y testimonial, ambas «figuras» - autor-personaje- no pueden ser entendidas únicamente como «funciones» en una ficción. Porque ¿podemos hablar solo de

10 En nuestra búsqueda por explotar y definir la noción de sujeto relato, seguimos a Guattari y Rolnik (2006) en su texto Micropolítica. cartografías del deseo, especialmente en su capítulo dedicado al análisis del sujeto, la subjetividad y la historia. Creemos que, junto a la idea de un sujeto en autoridad del «decir», se implican «modos de subjetivación singulares» o «procesos de singularización» ligados a nuevas lecturas de «lo dicho», lo que para la sicóloga y filósofa brasileña Suely Rolnik implicaría «rechazar» los modos de singularidad preestablecida o modelizada, que impiden pensar la realidad en términos variables y creativos (2006, p. 29-30). En esa lógica, podríamos pensar en los sujetos de relato situados en oposición a las llamadas «subjetividades capitalísticas» propias de lo que Rolnik y Guattari identifican como las «funciones de la economía subjetiva capitalística» (2006, p. 56); esto es, la discriminación, infantilización de los sujetos, los modos de temporalización impuestos por el orden mercantilista y los mecanismos de control estatal.

11 Planteamiento, como se sabe, discutido por Michel Foucault en «¿Qué es un autor?», texto que resulta de una conferencia de 1969 en la que el teórico se plantea una serie de interrogantes en relación con la figura del sujeto productor de obra y sus alcances en el contexto de la proclamada «muerte del autor», enunciada por Roland Barthes a fines de la década de 60. 
«figuras fictivas» cuando se trata de la representación de sujetos y de realidades, profundamente marcadas por la experiencia de la desigualdad, del racismo, de la explotación económica y social? Más aún: ¿podemos reducir la historia de la desigualdad a simples acontecimientos «ficcionales» cuando es la violencia la que habla en todas sus formas? ¿Cómo no atender, bajo el estatuto de la realidad, a literaturas como las de Arguedas o Colchado que interpelan la historia en sus marcas, en sus huellas y en sus voces de lo cotidiano?

Con todo, ¿cómo se expresa la voluntad subversora en los sujetos de relato? ¿Desde dónde construyen sentido histórico? La respuesta nos lleva al espacio de las microhistoricidades que habitan este tipo de textualidades, porque ¿desde qué otro lugar que no fuera el de la microhistoria, podría tener voz un sujeto de relato como el paradigmático Loco Moncada de Los zorros de Arguedas o el discurso solidario, político, de Sara Sarandonga en Hombres de mar?

\section{La impronta del Loco Moncada}

Un ejemplo inaugural y extraordinario de sujeto de relato lo constituye el Loco Moncada de El zorro de arriba y el zorro de abajo, de José María Arguedas, personaje social y textual que será referente primordial en nuestra lectura de Hombres de mar. Porque si hemos de considerar, siguiendo a Zohar (1999), que en la «red de fenómenos» que es la literatura, Los zorros de Arguedas se sitúa en la narrativa chimbotana en el centro del polisistema y constatando, además, que esta extraordinaria obra ha creado nuevos elementos para el repertorio, no es aventurado proponer, entonces, a la icónica figura del Loco Moncada - Ciriaco Moncada- como un modelo o arquetipo de sujeto de relato. Es más, sería imposible aproximarnos a la noción de sujeto de relato que aquí planteamos, sin invocar la figura liminar del paradigmático Moncada, pues, como se sabe, Los zorros de Arguedas es una obra profundamente marcada por la necesidad de registrar, desde su articulación polifónica, un proceso histórico en curso, razón por la cual ha llegado a ser referente ineludible para comprender el fenómeno de la modernización capitalista en el puerto de Chimbote ${ }^{12}$ y en el Perú. De tal suerte, el discurso político-social de Ciriaco Moncada se ha instituido, también, en precedente para la reflexión sobre el violento proceso transculturador del puerto. Arguedas logra plasmar en ese

\footnotetext{
12 Aunque la primera producción narrativa que aborda el mundo social chimbotano y la pesca como tema es el libro de cuentos Las islas blancas, de Julio Ortega, publicado en 1966, será El zorro de arriba y el zorro de debajo (1969) el texto clave que pondrá en el panorama literario peruano la tragedia social del Chimbote de la modernidad.
} 
«lisiado y desigual relato» ${ }^{13}$ no solo las tensiones y fuerzas de resistencia que prefiguraban los nuevos contornos de realidad peruana, sino, además, es capaz de articular nuevos marcos de creación en su propio proyecto escritural.

El mundo de la pesca, el frenesí mercantil y la devastación ambiental, la pobreza extrema de las barriadas, el espacio prostibulario, la acción transformadora del migrante serrano, sus propuestas, esperanzas y luchas sociales, cobran voz y fuerza explicativa en la conciencia crítica de un sujeto de relato excepcional: el Loco Moncada.

La continuidad del relato arguediano en la narrativa chimbotana y la influencia de la figura textual que llegó ser el Loco Moncada han marcado, sin dudas, la obra de Colchado, al punto de afirmar que su novela Hombres de mar se erige como «continuación» de Los zorros de Arguedas. De esta manera, la novela se configura en algún sentido como una suerte de «relevo» narrativo, como ocurre también con la obra Llora, corazón (2006), del escritor chimbotano Fernando Cueto.

Ahora bien, en términos de definir o caracterizar este mecanismo discursivo de resistencia que denominamos «sujeto de relato», fijamos nuestra atención en tres aspectos determinantes. En principio, diremos que esta estrategia escritural se sostiene en la preeminencia de la referencialidad extratextual y en los recursos del testimonio operados por el autor en la «puesta en escena» del sujeto de relato ${ }^{14}$. Es decir, en un contexto histórico-social concreto. Otro aspecto definitorio es la capacidad del sujeto de relato para producir discursos de resistencia-cultural y política. El sujeto de relato se define por su acción colectivizante en pos de hacer frente a las aciagas consecuencias del «progreso» que socavó vastos sectores de la sociedad peruana en el proceso de modernización capitalista. Asimismo, es importante recordar aquí que la marginalidad y la resistencia de Moncada estaban sostenidas por su «locura», por situación de precariedad y su «condición» de mulato. En este sentido, no hemos de olvidar que la

13 Con esta denominación, Arguedas autodefine, en la breve dedicatoria que inicia su última obra, El zorro de arriba y el zorro de abajo.

14 El personaje de Moncada ha generado una suerte de veneración por parte de la comunidad chimbotana y llega a ser «el gran admirado de las mujeres y los hombres que hoy (simbólicamente) aun a pesar de los años sigue en pie, como parte del imaginario popular que no lo olvida», como afirma Pedro Jacinto Pazos en su estudio «Realidad y ficción: las huellas del Loco Moncada en el imaginario popular a fines de los noventa en Chimbote». Para otros, Moncada es El profeta de la ecología (2014), como se le califica en el texto de Pedro Miranda Osorio. En este último texto, en el «Prólogo» de Jorge Smith, podemos leer desde su propia experiencia con Moncada, la voluntad política que guiaba los discursos del Loco Moncada, pues, tal como indica Smith, «no podía dejar de ser indiferente a las atinadas que eran sus críticas a lo que acontecía en esta convulsionada época, sobre todo de los años 60» (2014, p. 157). 
narrativa andina y los sujetos de relato que en ella operan se erigen desde la denuncia al modelo racista de dominación global característico del sistema-mundo moderno/capitalista y de la colonialidad del poder (Aníbal Quijano). Por ello es que en estas narrativas importa lo dicho, pero importan más aún los silencios que muchas veces sostienen la historia oficial.

Pues bien, es mediante su discurso que el sujeto de relato pone en crisis las acciones del «progreso» y de la modernidad. Moncada describe desde la particular visión de «el loco» situaciones de segregación, desarraigo, explotación, propias del modelo de sociedad basado en la riqueza de unos pocos y la pobreza de muchos. En la entrelínea de su discurso aparentemente descentrado y confuso yace una potente reflexión crítica sobre la historia social y política peruana. Injusticias, depredación y maltrato son instancias simbólicamente representadas en las performances de Moncada; estas se constituyen en verdaderos manifiestos políticos en contra de la depredación extranjera. Dice Moncada: «Aquí, en el Perú que decimos [...] no ha habido sino forasteros, extranjeros que han mandado. Nosotros no somos sino sirvientes de extranjeros»; "Los extranjeros son como los facinerosos engañadores de muchachas. Les ofrecen de todo y después que la han aprovechado, palo y escupe» (Arguedas, 1983, p. 54).

En el caso de Moncada, su discurso y la puesta en escena de ese discurso le otorgan un espacio de poder dentro del escenario de la marginalidad impuesta por un sistema basado en la desigualdad; sin embargo, su voz popular y culta, incluso por momentos académica, transforman su discurso en una suerte de irónico enaltecimiento a su condición de sujeto marginal: «Yo loco, negro, pescador pescado, voy a alimentarme de esta sangre del gallo de la pasión. ¡A vuestra salud, a vuestros pulmones! Vemos en el discurso de Moncada un tipo de pensamiento ideológico marginal con capacidad de producir cambio en la comunidad; un discurso de carácter profético. Este dice la verdad que dicen los locos (1983, p. 52), por lo que la locura sería un particular y radical espacio de microhistoricidad ${ }^{15}$. El discurso transgresor de la locura le permite decir y hacer, $y$, al mismo tiempo, la locura y el rechazo que esta produce en la comunidad lo protege de la respuesta frente al desenmascaramiento del poder oficial. La historia, diremos, se encarna - ya que, en más de un sentido, los sujetos de relato son sujetos testimoniantes - para repensar los «insumos» de la historia. Y es que la autoridad de los sujetos de relato radica, justamente, en su condición de actantes en el hecho histórico.

15 Como asegura Foucault (1992, p. 6), «suele ocurrir también que (al discurso del loco) se le confiere [...] extraños poderes, [...] el de enunciar una verdad oculta, el de predecir el porvenir, el de ver en su plena ingenuidad lo que la sabiduría de los otros no puede percibir». 
Valiéndonos de la teoría de la historia, podemos suponer con Fina Birulés $(1983)^{16}$, que, tal como ocurre en el texto histórico, los sujetos de relato se entraman a modo de «conciencias retrospectivas de intérpretes históricamente situados» (p. 22). Planteado así, el texto literario llega a ser una red de resonancias histórico-referenciales tejida por sujetos de relato (intérpretes históricamente situados) con múltiples procedencias socioculturales que hacen frente a la monocultura historiográfica.

Así planteada, la presencia de estas subjetividades históricas es compleja. No solo no son reducibles a la idea de "personaje» literario, como ya lo hemos indicado, sino que, además, su expresión y significancia van más allá de lo meramente individual, pues su naturaleza al ser histórica es también social y colectiva. Su acción en el texto literario no se limita a una dialéctica de sumisiones y hegemonías discursivas; menos aún se trata de un espacio de «placentera y falaz homogeneidad» (Bueno, 2004, p. 26). Antes bien, los sujetos de relato operan tendiendo puentes entre esa voz autorizada que ha determinado el hito, el hecho a narrar y que «dice» en el discurso histórico, y esas otras voces depreciadas que se resisten a los mutismos historiográficos, a los consensos discursivos y a los espacios clausurados en donde también ocurrió y ocurre la historia.

En consecuencia, es posible afirmar que en la narrativa andina, y en particular en obras como El zorro de arriba y el zorro de abajo y Hombres de mar, el peso que las variables subjetivas pueden tener en el quehacer historiográfico ${ }^{17}$ es sustancial, pues la historia no solo está atravesada por las «grandes» referencialidades biográficas, sino por las experiencias de las historias locales o microhistoria descritas, por ejemplo, en la voz de figuras sociales como el Loco Moncada.

\section{Voces recuperadas}

El Chimbote de Hombres de mar desmonta la «maravilla» del progreso y nos muestra un espacio geosocial sumido en el caos político, económico y social, en franca decadencia y en donde los conflictos no tardan en hacer estallar tensiones de larga data histórica anunciados ya en Los zorros de Arguedas. La bahía de El Ferrol comienza a experimentar su desintegración ecológica, producto de la contaminación de las numerosas fábricas pesqueras que se encuentran en Chimbote. Para 1973 la industria pesquera se encontraba en una compleja situación debido a la sobreexplotación de la anchoveta y al fenómeno climático de El Niño, todo lo cual dio

16 En su introducción al paradigmático texto de Arthur Danto Historia y narración (1983). 17 Punto de observación que otorga posibilidades de comprensión más profundas respecto del fenómeno del «micropoder» observado y enunciado - pero no plenamente descritopor Foucault. 
como resultado la quiebra de numerosas fábricas y empresas, con las consiguientes secuelas económicas y sociales. En un intento por paliar esta difícil situación, la dictadura de Velasco Alvarado estatiza el rubro y crea Pesca Perú. Luego, en 1976, bajo el régimen de Morales Bermúdez, la flota de Pesca Perú es vendida al sector privado. De ahí en adelante, otra serie de complejos fenómenos va a reconfigurar el caótico devenir de la sociedad chimbotana. Es un agitado océano de poderes que lamentablemente propenderá hacia la corrupción, el narco y la violencia generalizada cuya expresión más contundente será la emergencia de grupos como Sendero Luminoso y la práctica de la violencia estatal, lo que terminará por socavar la democracia peruana.

En la novela de Colchado la presencia de sujetos de relato activa el discurso historiográfico en una reescritura del complejo contexto histórico-social que intenta abarcar la obra. La figura de la activista social Sara Sarandonga es una de estas voces; así también, la voz del dirigente sindical Pedro Chinchayán o la mítica presencia del Viejo Tijera; todas estas "fuerzas discursivas» construyen y otorgan sentido histórico a la obra. Sus voces agentes reconfiguran, por ejemplo, la historia del sindicato de pescadores o la historia de la organización política estudiantil en el Politécnico de Chimbote. Estos anclajes extratextuales van configurando el tejido referencial mayor de la diégesis que intenta abordar, más o menos, 40 años de la historia social del Perú.

Pero si el espacio social y los sujetos de relato inscritos en Hombres de mar son cultural y socialmente diversos - como ocurre también en Los zorros - cabe preguntarnos: ¿qué ocurre con el hecho histórico narrado? En este caso, entenderemos que el hecho histórico es "versionado» en la multiplicidad de voces que se mueven en el espacio textual, lo que matiza y permea la objetividad historiográfica. Y aquí es preciso indicar que no solo encontramos en la novela un discurso social heteroglósico que propone distintas versiones de la historia, a partir de las diversas voces que los sujetos de relato producen, sino que además, se presentan sujetos heterogéneos, «múltiplemente situados» (Cornejo Polar, 1996) ${ }^{18}$, como ocurre con el Viejo Tijera que en la novela de Colchado gravita entre la dimensión del pensamiento mítico andino y la dimensión de las acciones «reales», en donde se desarrollan los hechos del Perú de la modernidad.

En la novela de Colchado las microhistorias organizan el relato en una

18 Uno de los aspectos que define al sujeto heterogéneo y, en específico, al sujeto migrante de Cornejo Polar es su necesidad y capacidad de duplicar su territorio, condenándolo según el autor, «a hablar desde más de un lugar», por lo que su discurso «es un discurso doble o múltiplemente situado» (1996, p. 841). 
apropiación dinámica de la memoria en la que yacen posiciones discursivas, lenguas, prácticas culturales y políticas, en permanente resistencia frente al olvido y la discriminación. De esta manera, el autor recupera y valida en el discurso historiográfico formas de «narrativa informal» como el rumor, para abordar la materia extratextual ${ }^{19}$. A modo de ejemplo, podemos mencionar la «revitalización» (antes que «reconstrucción») de la figura histórica de Luis Banchero Rossi ${ }^{20}$, «El Hombre», como se le conocía en el mundo popular, ícono y «leyenda» del empresariado peruano y del auge pesquero en Chimbote y que en la novela de Colchado aparece como Banchero Ross. Este sujeto histórico-social es investido con los rasgos «mágicos» otorgados por la tradición oral popular, situación que en gran medida valida los discursos informales como fuentes de relato histórico, permitiendo confrontar las indagaciones historiográficas convencionales, «oficiales» respecto de la figura de Banchero Rossi, su fortuna y su enigmática muerte. Veamos qué nos dice el relato en Hombres de mar

contaban que Bianchi Ross, el rey de la pesca, había tenido tratos con el Viejo Tijera, que para muchos es el mismo demonio [...] «Decían pues que el Viejo Tijera lo había hecho rico a cambio de su alma». Tal vez sea cierto, hom — dijo Muki-. Pues desde que murió Bianchi Ross ya no vuelto levantar pesca como antes en todo litoral. Muerte suya, además, no sido esclarecida aún. ¿Quién realmente lo mató? Eso nadie lo sabe [...] Pero el verdá te diré, amigo, lo que yo más creo es que Bianchi Ross hizo rico con droga más que con pesca (Colchado, 2011, p. 153).

Como se advierte en esta cita, aunque «sospechado» por la historiografía "certificada» ${ }^{21}$, el relato de los pescadores de Chimbote ha sido, sin embargo, vedado por los discursos oficiales; el rumbo explicativo, en este caso, se vincula a la construcción discursiva del rumor para otorgar respuestas posibles a ciertos vacíos del discurso historiográfico oficial, pues,

19 En este ámbito de cosas, resulta sumamente importante en la obra el discurso oral andino que se infiltra a través de las variadas posibilidades que otorga el willakuy en el texto escrito. Este. irrumpe en la escritura como posibilidad transculturada del discurso andino. Diremos que en la obra de Colchado el willakuy le otorga a la escritura las posibilidades expresivas consubstanciales a la oralidad, de forma tal que la fijeza de la letra se subvierte para convocar un espacio epistemológicamente disidente al poner en cuestión el soporte tradicional de la novela: la escritura.

20 Son innumerables los relatos y escritos periodísticos e historiográficos que señalan la década de 1960 como la década de Banchero Rossi. Se destaca que, en virtud de sus cualidades extraordinarias y no exentas de cierto «misterio», posicionan la figura del empresario como una «leyenda».

21 Al revisar artículos de prensa, textos de historia y diversos espacios informativos en redes sociales en internet, se puede colegir que la figura de Banchero está bastante «blindada», aun cuando hay muchas voces que ponen en cuestión la imagen «benefactora» del personaje. 
efectivamente, en el ámbito de la historia «popular», inclusive de la prensa más oficializada, circula la duda respecto a los vínculos del empresario con el narcotráfico y, en un ámbito ya más oficial, tampoco se ha podido dar una respuesta «objetiva» respecto de la muerte del empresario Luis Banchero Rossi.

Los sujetos de relato releen el extenso trayecto histórico posarguediano desde una perspectiva polifónica, pues en obras como Hombres de mar la memoria social, siguiendo a Grez (2007), no puede ser tratada como «una» memoria social, sino como «pluralidad de memorias sociales» (s. n.). Lo dicho hasta aquí supone el derecho a «versionar» la historia y no la «verificación» de hechos, como podría suponerse. La «autorización» de otras versiones de la historia en el espacio novelado implica tanto complementar como impugnar las aserciones históricas hegemónicas y, al mismo tiempo, se pone en evidencia la necesidad de la literatura de romper con ciertos modelos discursivos dominantes y con sus intereses, apelando a otras formas y prácticas discursivas que históricamente han hecho frente a los modelos impuestos por "alta cultura», la academia y el mundo de la ciudad letrada. De manera que, como vemos, es mediante el rumor, el relato mítico, el «dicen», el diálogo popular y cotidiano que los sujetos de relato levantan sus discursos, ofrecen respuestas discrepantes y cobran su estatuto de sujetos políticos, es decir, con incidencia en la realidad, en el bien común, en el cambio social.

\section{Sara Sarandonga y la historia/Historia del Chimbote posar- guediano}

Hemos seguido la huella de Los zorros para entender en Hombres de $\operatorname{mar}^{22}$, la presencia de sujetos sociales como el enigmático Viejo Tijera o Pedro Chinchayán, de quien nos dice Colchado «vive actualmente en el puerto y aunque ya no es pescador, [...] igual, sigue luchando con la misma entereza y pasión en favor del gremio al cual ahora pertenece» (Colchado, 2012). Incluso, podríamos pensar en el mismo José María Arguedas que se incorpora a la diégesis novelada y a la revitalización social e histórica de la novela.

\footnotetext{
22 Personaje de quien nos dice Colchado: «Hay muchos relatos sobre él en los que se narra su vida solitaria y alejada de la ciudad. Vivía en el cerro El Dorado, junto al mar, o en las islas que rodean la bahía. Se sabe que vino de los Andes, de un pueblo del departamento de La Libertad, a trabajar en las campiñas de Chimbote, que tuvo familia, pero que de pronto, no se sabe por qué razones, se aisló del mundo. Solía ir solo a veces a la ciudad, dicen que arreando un burro, a proveerse de algunas cosas indispensables Teobaldo Arroyo Icochea, es un periodista que lo entrevistó por los años cincuenta cuando se hallaba enfermo en el hospital de La Caleta. Tenía más de cien años (la entrevista aparece en un libro de recuerdos sobre Chimbote» (Colchado, comunicación personal, setiembre de 2015).
} 
Sin embargo, nos interesa destacar la figura de Sara Sarandonga ${ }^{23}$, bailarina, cantinera y luchadora social, pues a través de ella la historia/ Historia en Hombres de mar cobra voz y cuerpo ${ }^{24}$. Zoila Herfilia Carmen Valdivia Paz, conocida en el puerto como Sara Sarandonga, es presentada en la obra como:

una mujer espigada, flaquita, algo marchita, de tez clara y facciones agradables, muy querida por los pescadores [...] que en su juventud había sido bailarina en los centros nocturnos de la ciudad en tiempos en que abundaba el billete en el puerto [pero que ] con la crisis que vino después cuando el pescado se alejó de [las] costas debido al terremoto de la década del 70, según unos, por la muerte de Bianchi Ross[...] tuvo que refugiarse en los bares de mala muerte, los llamados huecos (Colchado, 2011, p. 258).

Sarandonga vivió la compleja experiencia de la modernidad en el Chimbote posterior a la época «dorada» de la industria pesquera a fines de la década de 1960, cuando los pescadores-nos cuenta en entrevista de César Quispe (2008):

eran los reyes de las cantinas [...] Ellos pedían por caja las cervezas, y la mayoría cerraban las cantinas. Cuando ellos se iban al baño no necesitaban papel, se limpiaban con los billetes que tenían en los bolsillos, en sus pantalones no habían monedas, solo «cheques.

La Tía Sarandonga es un sujeto de relato que nos habla del «bajo fondo del puerto»; de los bares, del trasnoche, del night club, pero, al mismo tiempo, construye un potente discurso en torno a la necesidad política y solidaria de luchar en un contexto asolado por mercantilismo, el narcotráfico y la violencia. Como lo haría Moncada en Los zorros de Arguedas, en Hombres de mar Sarandonga se reconstruye en su propio discurso socialhistórico, desde la vivencia de la desigualdad social y económica, desde su discurso de bares y luchas: «la Sarandonga denuncia la migración campesina-indígena hacia la urbe —el desborde popular, como lo ha llamado Matos Mar (1986)_, el racismo, la violencia político-estatal y revolucionaria de Sendero y toda la gama de aciagas consecuencias provocadas por el modelo político-económico predominantemente capitalista que se asienta en el Perú de las décadas de 1960 y 1970 (Montoya, 1978), con

23 Zoila Valdivia Paz conocida como Sarandonga o «La Tía Sara» falleció en enero de 2017, a los 81 años en un hospital de esa localidad, según lo consignó el medio electrónico el Diario de Chimbote. Al igual que Moncada, Sara Sarandonga se ha transformado en ícono social y cuenta de ello, es el gran número de seguidores que tiene en la red.

24 El cuento "La tía Sara. La Sarandonga», de Víctor Unyén Velezmoro, de 1997, la crónica «De cómo encontrar la libertad», de Augusto Rubio Acosta, de 2007, son ejemplos claros de la popularidad de la activista social en Chimbote. 
epicentro en el puerto de Chimbote. Porque para esos días, nos cuenta Sarandonga:

el Sindicato de Pescadores de Chimbote y Anexos queda bajo el control de la gente del MLR, con la anuencia solapada de las autoridades [...] el gobierno de Velasco Alvarado anuncia la inminente estatización de la industria pesquera [y la] estatificación de la pesca [...] que les cayó como agua helada a los empresarios pesqueros. Pero ya qué iban a hacer. Si los gringos yanqui, con ser lo que eran, se habían quedado con la boca cerrada ante la nacionalización del petróleo en Talara (Colchado, 2011, p. 176).

Como se observa en la cita anterior, Sarandonga tiene una voz política y una conciencia crítica respecto del panorama en que le ha tocado vivir. En este sujeto de relato, no se puede obviar el hecho de que su disidencia está dada, en parte, por la pertenencia y el sesgo de género inscrita en su subjetividad. Hay, indudablemente, una posición de género desde donde se levanta el discurso social que ella produce y que no puede desligarse de su experiencia vital. Sarandonga se hace a sí misma sujeto de derecho. En su discurso social-sindical se expresa además, una memoria del cuerpo que es también, una memoria política, pues ella:

la exbailarina venida a menos, pero muy estimada como luchadora social [...] Es ella la que en las marchas populares grita a voz en cuello con su voz aguda y estridente las consignas de los manifestantes. $\mathrm{O}$ la que también reparte volantes por calles y plazas y organiza con las mujeres de los obreros las ollas comunes (Colchado, 2011, p. 69).

Su oficio de bailarina del que podríamos pensar está «hecho solo para satisfacción del espectador masculino». Sin embrago, es significado en el texto como parte del quehacer político-sindical de la bailarina, y ese vínculo singular es constantemente remarcado en el texto. Veamos:

En los movimientos de Sara Sarandonga, que andaría arriba de los cuarenta, se le notaba todavía ese aire farandulero que se le había quedado de sus tiempos de bailarina de night club. Piero Peter al verla moverse de modo tan sensual y provocativo, no pudo hacerse a la idea de que fuera la misma persona que en las marchas de protesta solía avanzar muy seria y solemne, llevando bien alto la bandera peruana, mientras arengaba a voz en cuello, ¡Griten más fuerte, compañeros, para que oiga la dictadura!... Y era ella misma quien soltaba también las consignas a vocerarse (Colchado, 2011, p. 456).

La intención historiográfica presente en las «marcas» extratextuales, adicionales, que, en este caso, están dadas por la presencia del poeta chimbotano Piero Peter. Sara Sarandonga no es un personaje estable, «terminado». A lo largo de la novela se va configurando el personaje polí- 
tico y social que llega a ser Sarandonga. La presencia y el discurso de Sara Sarandonga - ya sea en su voz o en la voz de otros narradores actantes en su espacio - colocan en la superficie textual referencialidades criticas que desvelan formaciones sociales que, para entonces, intentaban dar un sentido práctico y «real» al concepto de democracia social y política. Por lo mismo, el texto se desborda de sus marcos estético-literarios, porque se trata de la historia social, de las vivencias y de la experiencia de Sarandonga, y que, por lo mismo, mantiene en la novela su nombre extratextual, pues ella tiene la autoridad de «decir» y su discurso es la versión de la historia social que no se contó. Así, leemos en la novela:

Dice uno de los borrachitos del bar: Cuéntanos, Sarita, ¿cómo fue que entraste a las luchas del pueblo? Una mañana, dice, en que yo me hallaba pensativa mirando por la ventana del cuarto de mi amiga Rosa, vi pasar por la calle un numeroso grupo de manifestantes de construcción civil que me llamó la atención. Hasta ese momento yo había estado pensando seriamente en que a esas alturas de mi vida, en que ya no era una jovencita, no estaba bueno vivir ocupada solo en mi bienestar personal, sino que, para no sentirme vacía, algo debía hacer también por aquellos que, se podía decir, eran los que me sustentaban económicamente. O sea pues, mis amigos pescadores, siderúrgicos y todos los demás. Consideraba que no era suficiente alegrarlos solo con mi conversación, mi risa y mi baile, que eran muy necesarios, sí, claro, para relajarlos un poco de la chamba dura de la semana, pero había que pensar también que últimamente pasaban por serios problemas económicos, debido a la crisis de la pesca luego del terremoto, y que hacía falta ${ }^{25}$.

Tenemos a una mujer que se apropia del relato construyendo su propio discurso mediante su acción política basada en la solidaridad como principio ideológico, pues como indica: «Nosotros aquí comiendo y bailando tranquilos, mientras otros compañeros, como nuestro pata Plasencia, el motorista de Pescamar, agonizan en el hospital, o están recluidos en las cárceles, o los policías los tienen haciéndoles botar piedras en las pistas a punta de metralleta» (Colchado, 2011, p. 458). Ese discurso tiene un lugar de discusión y enunciación, el bar y unos interlocutores que difícilmente la discursividad histórica oficial validaría como fuentes. Aquí, el sentido político del discurso radica en la vivencia de la desigualdad y en práctica política a la que conduce.

25 El escritor chimbotano Augusto Rubio Acosta (2007), en su crónica «De cómo alcanzar la libertad», dedicada a la activista social, afirma: «Ojalá la mayoría de mujeres chimbotanas tuvieran el coraje de enfrentarse a su destino - pensamos_-, ojalá tuvieran la sensibilidad social y la necesidad de libertad a flor de piel. Ojalá hubiera Saras en cada empresa, en cada barrio, en cada comunidad, en cada ministerio, para hacer del país un Perú distinto». 
Hacia el final de la novela, el devenir histórico social alcanzará hasta entrado el 2000: la Marcha de los Cuatro Suyos, la huida de Fujimori y su insólita y vergonzosa renuncia a la presidencia desde Japón mediante un fax. Precisamente, cuando se prepara la Marcha de los Cuatro Suyos, vemos que el discurso de Sarandonga se ha transformado en memoria colectiva, como una conciencia crítica de la realidad que la coloca en un lugar de respeto absoluto. Así lo explica un esporádico narrador:

Una señora delgada, de tez clara y cabellos largos, que yo vi arengando a la multitud, pasó corriendo por mi lado, asustada, volviendo el rostro de cuando en cuando para constatar si los que la seguían estaban próximos. Dijeron que se trataba de la luchadora social Sara Sarandonga que huía de los guardias que la venían persiguiendo en un carro. Yo la había visto ya otras veces presidiendo las marchas en las huelgas, mas nunca como hoy en apuros (496).

El discurso de Sara es su propia práctica política, porque el bien común va más allá de la palabra; para ella, la política sigue siendo vivencia y cuerpo. Así nos explica que cuando «un grupo de pescadores que la escuchaba atento, un guardia me vino a amenazar con su revólver. Tú ya eres muerta para mí, me dijo. Yo no me chupé, compañeros. ¡Dispara, pue, baboso!, le dije, ¡dispara! Y entre mí dije: Qué me importa, muero yo o muere él, y me lancé a quitarle el arma» (Colchado, 2011, p. 496).

Tenemos pues en el texto algo más que personajes. La voz de Sara Sarandonga es constantemente validada por su estatuto testimonial que, como se ha dicho, ha sido recuperado y documentado por el autor. Ella relee desde los márgenes del discurso social los discursos de poder, los mecanismos y modulaciones de la violencia política, estatal, económica y racial, pero también, en cuanto sujeto de relato, el discurso de Sarandonga es una respuesta y es acción. Se trata, finalmente, de validar y reconocer en sujetos como Sarandonga las nuevas formaciones sociales y culturales obviadas, muchas veces, por el discurso historiográfico de cuño academicista.

\section{Algunas conclusiones}

La naturaleza problemática de la bien llamada «monumental novela» de Colchado, Hombres de mar, está dada en gran medida por la diversidad de voces intencionadas historiográficamente, que se imbrican en la obra, poniendo en la superficie textual diversas versiones de la historia y, por consiguiente, diversas capas de realidad y memorias, muchas veces diametralmente opuestas. La estructura polifónica de Hombres de mar, más que activar memorias de consenso a través de las voces de sujetos de relato, moviliza una pluralidad de memorias sociales disputando el 
derecho a contar cada una su propia verdad o versión del hecho experimentado. En este sentido, el texto en su heterogeneidad sociocultural llega a ser esa «zona de ambigüedad y conflicto», de la que nos habla Cornejo Polar al definir las literaturas heterogéneas. En escrituras éticas como las de Arguedas o Colchado el sujeto que enuncia sí importa. Con todo, no se trata aquí de negar la objetividad factual de la Historia en cuanto disciplina, sino de reconocer las fisuras de su enunciación univoca por donde se infiltran aquellas voces desautorizadas por la oficialidad y que en su acción extra e intra textual, nos recuerdan lo concreto del «hecho literario». 


\section{REFERENCIAS BIBLIOGRÁFICAS}

ANGENOT, M. (2010). El discurso social. Los límites de lo pensable y lo decible. Buenos Aires: Siglo XXI.

ARGUEDAS, J. M. (1983). El zorro de arriba y el zorro de abajo. Lima: Horizonte.

BIRULÉS, F. (1989). Introducción. En A. Danto. Historia y narración (pp. 9-27). Barcelona: Paidós.

BUENO, R. (2004). Sobre la heterogeneidad literaria y cultural de América Latina. En Antonio Cornejo Polar y los avatares de la cultura latinoamericana (pp.19-36). Lima: Fondo Editorial de la Universidad Nacional Mayor de San Marcos.

CASTRO, D. (2005). Una reflexión. En El encuentro peruano de narradores en Madrid. Omnibus. Recuperado de http://www.omnibus.com/congreso/ opiniones/dantecastro.html

CHARTIER, R. (1999). Trabajar con Foucault: esbozo de una genealogía de la «función-autor». Signos Históricos, 1, pp. 11-27.

COLCHADO, Ó. (2011). Hombres de mar. Lima: Alfaguara.

CORNEJO, A. (1989). Los sistemas literarios como categorías históricas. Elementos para una discusión. Revista de Crítica Literaria Latinoamericana, 29, pp. 19-25.

(julio-diciembre de 1996). Una heterogeneidad no dialéctica: Sujeto y discurso migrantes en el Perú moderno. Revista lberoamericana, LXII(176-177), pp. 837-844.

DANTO, A. (1989). Historia y narración. Ensayos de filosofía analítica de la historia. Barcelona: Paidós.

DEGREGORI, C. I. (2007). Entre el fuego y la calandria. Visión del Perú desde la narrativa andina. Crónicas urbanas, 12, pp. 55-66.

EVEN-ZOHAR, I. (1999). Factores y dependencias de la cultura. Una revisión de la teoría de los polisistemas. Teoría de los polisistemas. Madrid: Arco.

FOUCAULT, M. (1999). ¿Qué es un autor? En Entre filosofía y literatura. Obras esenciales. Volumen I. Barcelona: Paidós.

GREZ, S. (2005). Historiografía, memoria y política. Observaciones para un debate. Recuperado de http://web.uchile.cl/vignette/cyberhumanitatis/ CDA/texto_simple2/0,1255,SCID\%253D21039\%2526ISID\%253D730,00. html

GUATTARI, F. y Rolnik, S. (2006). Micropolítica. Cartografías del deseo. Madrid:Traficantes de Sueños. 
HARSHAW, B. (1997). Ficcionalidad y campos de referencia. En G. Antonio. Teorías de la ficción literaria (pp.126-158). Madrid: Arco Libros.

HUAMÁN, M. Á. (2006). Escritura utópica y crítica estético-política: de Churata a Colchado. Escritura y Pensamiento, 19, pp. 7-22.

MIRANDA, P. (2014). Moncada, el profeta de la ecología. Chimbote: Río Santa Editores.

MATOS-MAR, J. (1986). Desborde popular y crisis del Estado. El nuevo rostro del Perú en la década de 1980. Lima: Instituto de Estudios Peruanos.

MONTOYA, R. (1978). El carácter predominantemente capitalista de la economía peruana actual. (1960-1979). Lima: Mosca Azul Editores.

ORTEGA, J. (2010). El sujeto dialógico. Negociaciones de la modernidad conflictiva. Ciudad de México: Fondo de Cultura Económica.

OSORIO, J. (1995). La narrativa andina. Sieteculebras, 8, pp. 9-10.

PAZOS, J. P. (2004). Realidad y ficción: las huellas del «Loco Moncada» en el imaginario popular a fines de los noventa en Chimbote. En W. Kapsoli (Comp.). Zorros al fin del milenio (pp. 87-110). Lima: Centro de investigación Universidad Ricardo Palma.

WHITE, H. (1992). Metahistoria, la imaginación histórica en la Europa del siglo XIX. Ciudad de México: Fondo de Cultura Económica.

escritos. Barcelona: Paidós. (2003). El texto histórico como artefacto literario y otros 